\title{
First confirmed records of Rüppell's Vultures (Gyps rueppelli) in Malawi.
}

\author{
Olivia Sievert $^{1^{*}}$, Craig Reid ${ }^{2}$, Andre Botha ${ }^{3}$ \\ ${ }^{1}$ Department of Conservation Ecology and Entomology, University of Stellenbosch, South Africa \\ ${ }^{2}$ African Parks, Bryanston, South Africa \\ ${ }^{3}$ Endangered Wildlife Trust, Modderfontein, South Africa \\ * Corresponding author: olivia.sievert@gmail.com
}

http://dx.doi.org/10.4314/vulnew.v78i1.4

There is little contemporary research or literature on the ecology and movements of vultures in Malawi (see, Roxburgh \& McDougall 2012, Galanou 2016, Sievert et al. 2018). Consequentially, the Convention on the Conservation of Migratory Species' Vulture MultiSpecies Action Plan, has identified Malawi as a considerable knowledge gap for eastern and southern African vulture populations (Botha et al. 2017). Historical information on the distribution of vultures in Malawi is also sparse. However, four species have been recorded as residents in Malawi, namely: African White-backed Vulture Gyps africanus, White-headed Vulture Trigonoceps occipitalis, Hooded Vulture Necrosyrtes monachus and Palm-nut Vulture Gypohierax angolensis (Botha et al. 2017). Additionally, two species have been identified as non-breeding visitors to Malawi, the Lappet-faced Vulture Torgos tracheliotos and the Cape Vulture Gyps coprotheres (Botha et al. 2017).

In the southern region of Malawi, vulture monitoring in the form of opportunistic road counts and camera trapping at carcasses, has been underway in Liwonde National Park (14 ${ }^{\circ} 50^{\prime} 31.5^{\prime \prime S}$ $35^{\circ} 20^{\prime} 59.9^{\prime \prime E}$; Figure 1) since 2017. On the $6^{\text {th }}$ of November 2018 during monitoring, an adult Rüppell's Vulture Gyps rueppelli was spotted feeding on an impala Aepyceros melampus among
African White-backed Vultures and a Marabou Stork Leptoptilos crumeniferus (Figure 2). This was the sole report or record of Rüppell's Vultures in Liwonde National Park that year. However, in 2019, a large bull African elephant Loxodonta africana was found deceased through natural causes in the central section of the park. Camera trapping at this carcass took place for 52 days $\left(5^{\text {th }}\right.$ of May $-11^{\text {th }}$ of July) during which time Rüppell's Vultures were photographed. Over the course of 2019, a total of eight camera trap days yielded photos of suspected Rüppell's Vultures. An additional report in 2019 totalled the number of suspected Rüppell's Vulture sightings in 2019 to nine. Five of these sightings had high enough quality images to allow species confirmation (Figures 3,4,5,6,7), leaving four sightings inconclusive.

Plumage of the individuals photographed confirms a minimum of two separate Rüppell's Vultures, an adult and an immature, visiting the park in 2019. However, given the number of inconclusive sightings the authors cannot rule out the presence of additional individuals. Initial species identification was made based on plumage while referencing Rodriguez \& Elorriaga (2016). Images were then sent to experts with extensive experience working with the species for final confirmation. 


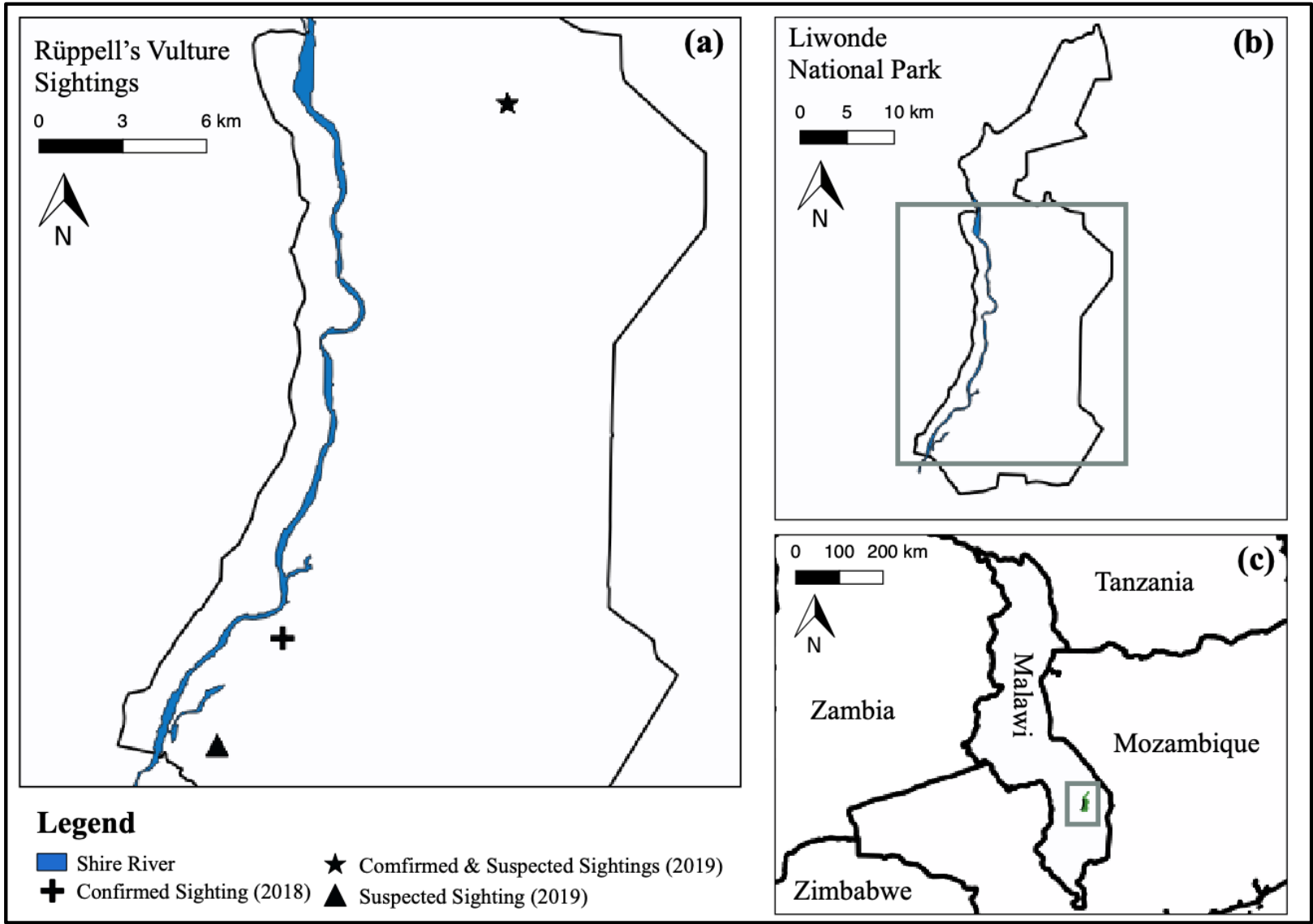

Figure 1: Map of (a) Rüppell's Vulture sightings in Liwonde National Park (2018-2019), (b) Liwonde National Park with indication to the area of sightings (c) the location of Liwonde National Park in Malawi.

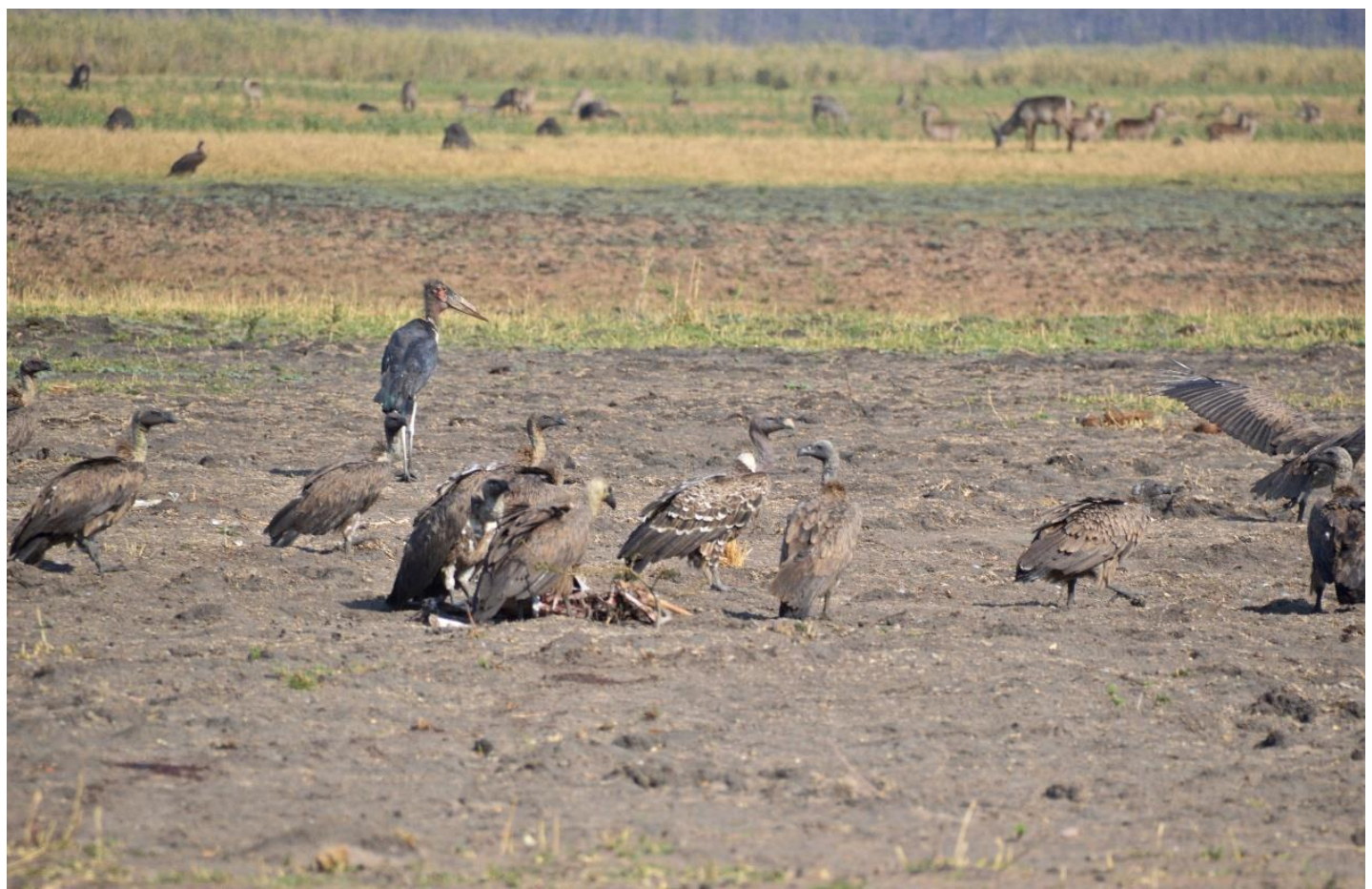

Figure 2: Adult Rüppell's Vulture photographed at an impala carcass with African White-backed Vultures and Marabou Storks, $6^{\text {th }}$ November 2018. 


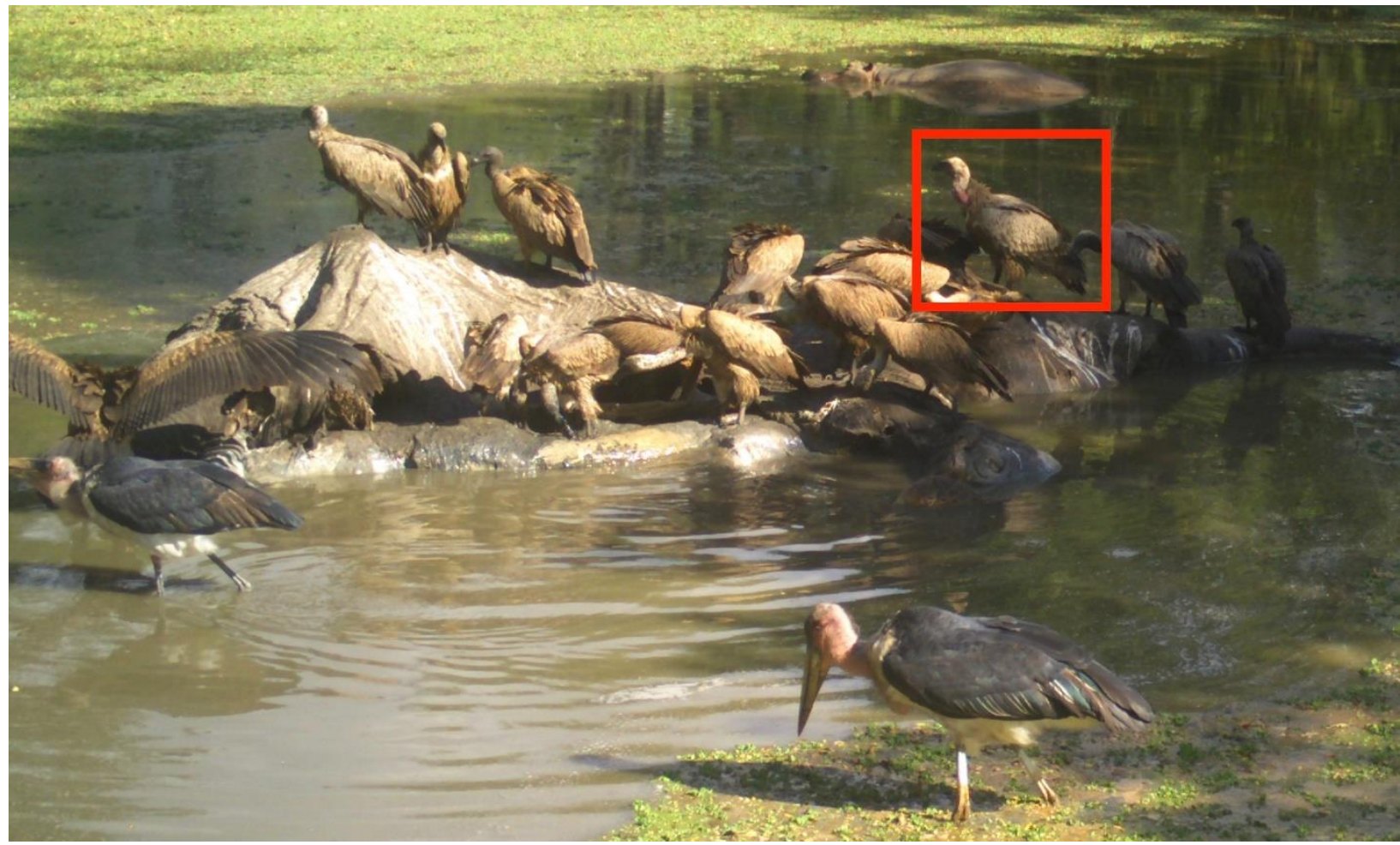

Figure 3: A camera trap image of an immature Rüppell's Vulture (indicated by red box) feeding on an elephant carcass with African White-backed Vultures and Marabou Storks, $3^{\text {rd }}$ June 2019.

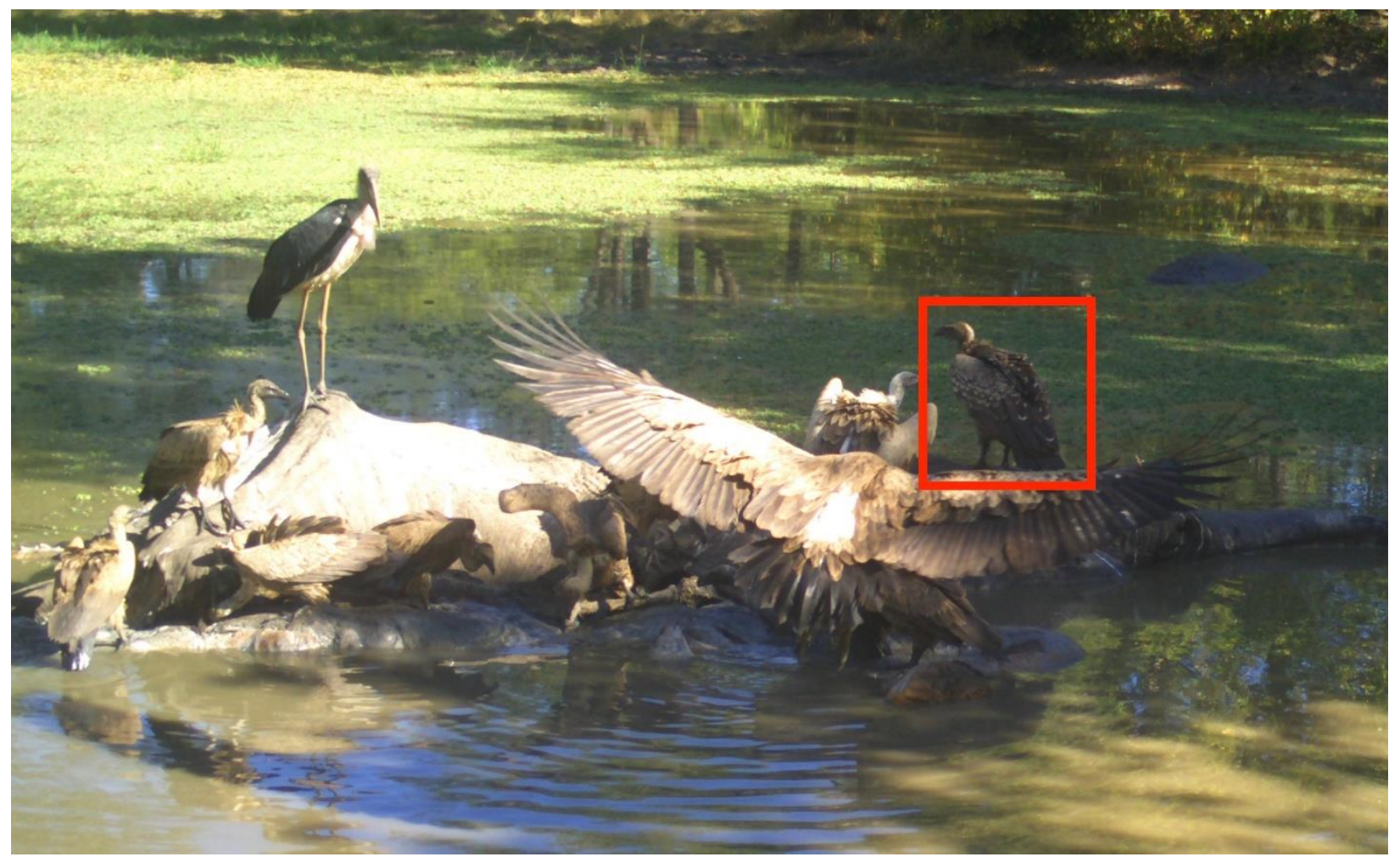

Figure 4: A camera trap image of an adult Rüppell's Vulture (indicated by red box) resting on an elephant carcass with African White-backed Vultures and Marabou Storks, $6^{\text {th }}$ June 2019. 


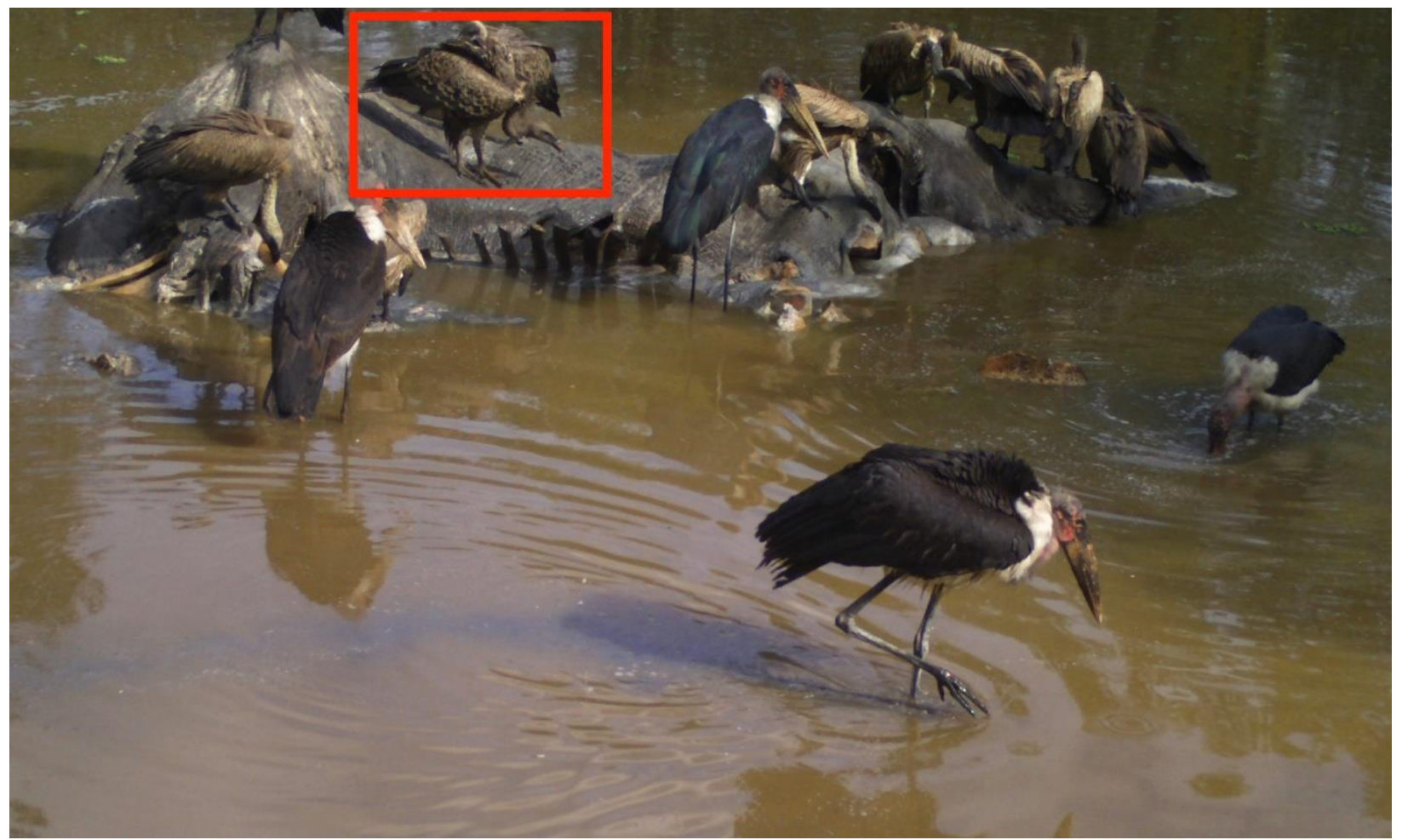

Figure 5: A camera trap image of an adult Rüppell's Vulture (indicated by red box) resting on an elephant carcass with African White-backed Vultures and Marabou Storks, $16^{\text {th }}$ June 2019.

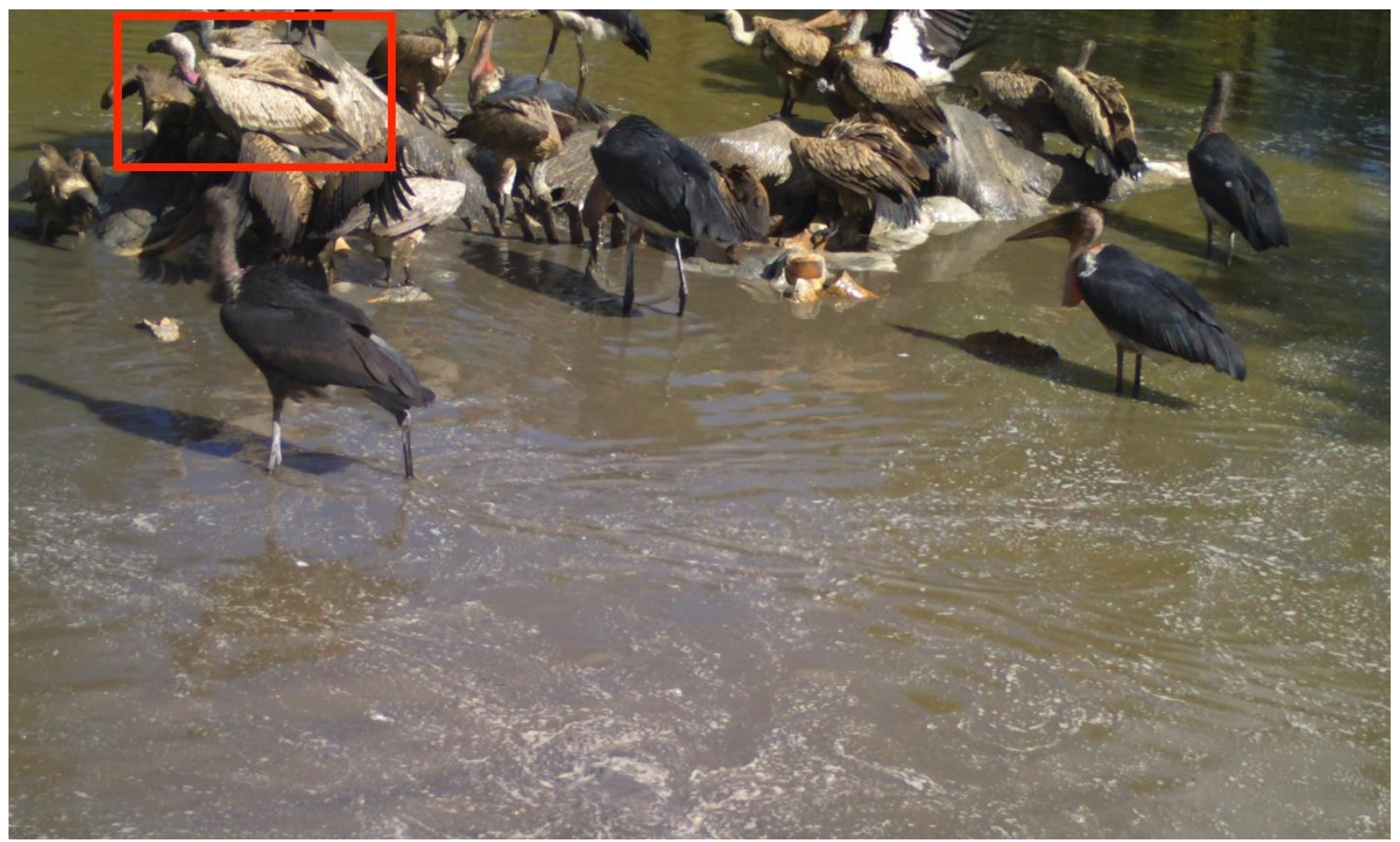

Figure 6: A camera trap image of an immature Rüppell's Vulture (indicated by red box) feeding on an elephant carcass with African White-backed Vultures and Marabou Storks, $19^{\text {th }}$ June 2019. 


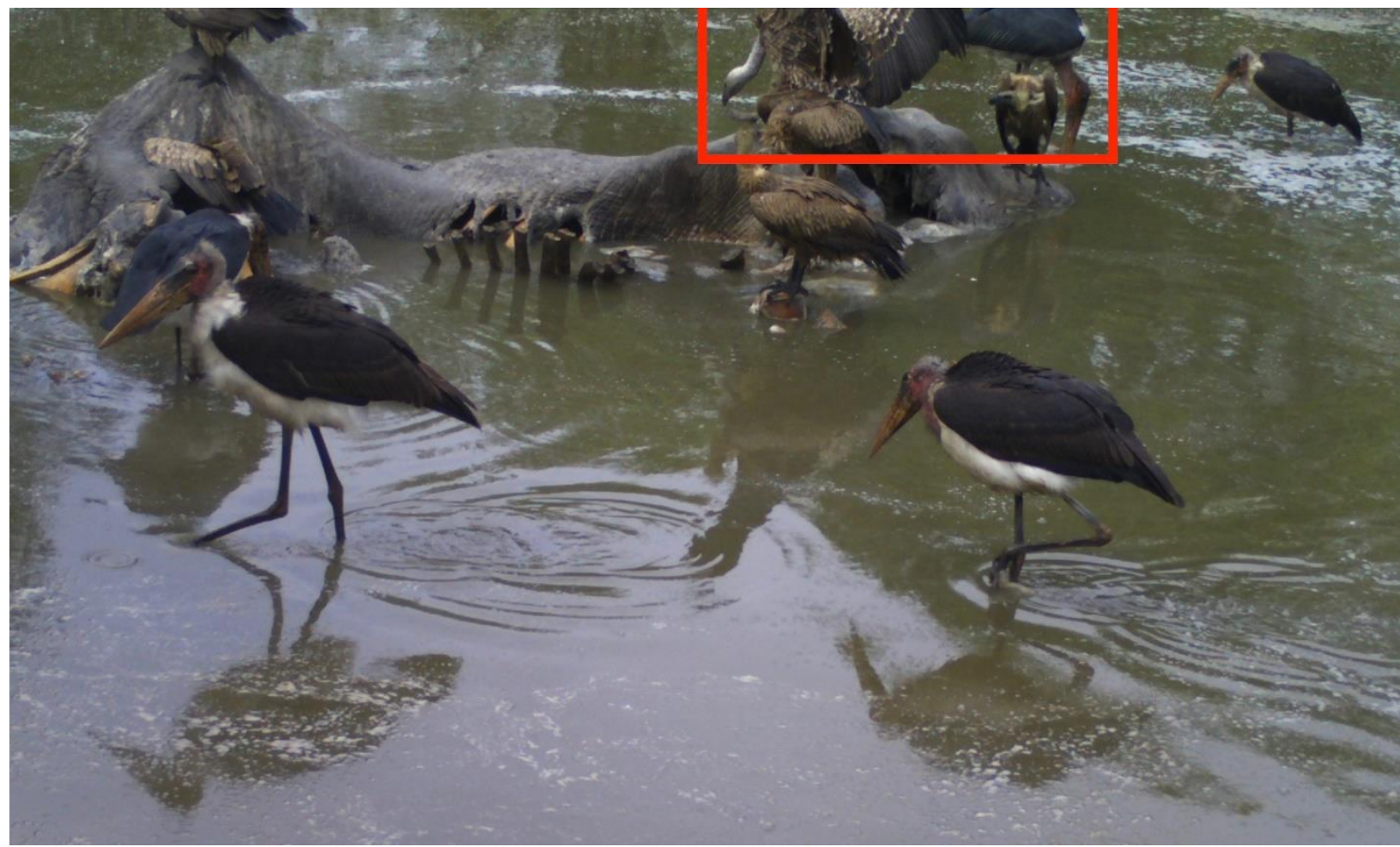

Figure 7: A camera trap image of an adult Rüppell's Vulture (indicated by red box) feeding on an elephant carcass with African White-backed Vultures and Marabou Storks, 22 ${ }^{\text {nd }}$ June 2019.

To the authors' knowledge, these are the first records of Rüppell's Vultures in Malawi. Rüppell's Vultures occur throughout the Sahel region and the East African savanna regions. A recent study of a satellite tagged adult Rüppell's Vultures revealed a range size of $71,990 \mathrm{~km}^{2}$ over ten months (Virani et al. 2012). Moreover, individuals have been recorded on several occasions outside of the species range in both the Iberian Peninsula and southern Africa (Rodriguez \& Elorriaga 2016, Botha et al. 2017, Botha \& Román 2018). However, prior to our report, there has been no definite evidence of the species in Malawi. The recent sightings in Liwonde National Park coupled with the recent record in central Mozambique (Botha \& Román 2018), roughly $443 \mathrm{~km}$ southwest of Liwonde National Park, suggests this species may be an uncommon visitor to Malawi.
Considering the alarming decline in vulture populations across Africa and the large multicountry home ranges that many vulture species inhabit, the development of cross-country legislation is vital in the conservation of remaining populations (Botha et al. 2017, Buechley et al. 2018). However, the large knowledge gaps that remain must be addressed in order to create informed conservation initiatives. Since the initiation of Liwonde National Park's vulture monitoring in 2017, five species have been identified across 241 sightings, including the before mentioned Rüppell's Vultures. Although Rüppell's Vultures may have occurred sporadically in Malawi previously, no formal records could be located, thereby demonstrating the importance of long-term monitoring in expanding our knowledge of the ranging behaviour of Africa's vulture species. 


\section{Acknowledgements}

We are grateful for feedback from reviewers and thank Munir Virani, Darcy Ogada and Simon Thomsett for assisting with the confirmation of species identification.

\section{Ethical Standards}

Vulture monitoring in Liwonde National Park is conducted by African Parks Liwonde. African Parks has the required authorizations and mandate to undertake vulture monitoring in Liwonde National Park.

\section{References}

Botha, A.J., Andevski, J., Bowden, C.G.R., Gudka, M., Safford, R.J., Tavares, J. \& Williams, N.P. 2017. Multi-species Action Plan to Conserve African-Eurasian Vultures. CMS Raptors MOU Technical Publication No.4. CMS Technical Series No.33. Coordinating Unit of the CMS Raptors MOU, Abu Dhabi, United Arab Emirates.

Botha, A. \& Román, J.R. 2018. First confirmed record of Rüppell's Vulture Gyps rueppelli from the Gorongosa National Park, central Mozambique. Vulture News. 74: 35-38.

Buechley, E.R., McGrady, M.J., Çoban, E. \& Sekercioglu, Ç.H. 2018. Satellite tracking a wide-ranging endangered vulture species to target conservation actions in the Middle East and East Africa. Biodiversity Conservation. 27: 2293-2310.

Galanou, E. 2016. Vulture ecosystem services report: the case study of Nyika National Park. Nyika Vwaza Trust Research Report. Nyika Vwaza Trust. Malawi.

Rodríguez, G. \& Elorriaga, J. 2016. Identification of Rüppell's Vulture and White-backed Vulture and vagrancy in the Western Palaeartic. Dutch Birding. 38(6):349-375.

Roxburgh, L. \& McDougall, R. 2012. Vulture poisoning incidents and the status of vultures in Zambia and Malawi. Vulture News. 64: 33-3.

Sievert, O., Reid, C. \& Botha, A. 2018. The re-emergence of African White-backed Vultures (Gyps africanus), White-headed Vultures (Trigonoceps occipitalis) and Lappet-faced Vultures (Torgos tracheliotos) in Liwonde National Park, Malawi. Vulture News. 74: 12-19.

Virani, M.Z., Monadjem, A., Thomsett, S. \& Kendall, C. 2012. Seasonal variation in breeding Rüppell’s Vultures Gyps rueppellii at Kwenia, southern Kenya and implications for conservation. Bird Conservation International. 22(3): 260-269. 